\title{
A Framework for Developing Effective Technology-Enabled Distance Education Programs in Management: A Study of a Video Conference-Based Program in an Indian Perspective
}

\author{
Jaydeep Mukherje \\ MDI, India \\ Mukti Mishra \\ Victoria University, Australia
}

\begin{abstract}
A major problem in delivering quality management education to working executives in India has been the inability of the candidates to leave their job for a prolonged period of time to attend the on-campus management programs. With the proliferation of two way Video Conferencing (VC) facilities across the country, as well as the use of Internet technology, this limitations could quite effectively be overcome for both students and management educators.
\end{abstract}

\section{Keywords}

India, Video conferencing (VC), management education, online education

\section{Introduction}

There has been a very significant un-met need for quality management education for working executives in India. One of the major bottlenecks has been the inability of the candidates to leave their job for a prolonged period of time to attend the on-campus management programs. From an educator's point of view, effective management education could not be imparted without the possibility of a reasonably high degree of student-faculty interaction and more significantly, student to student interaction (Conaway, Easton and Schimdt 2005). Thus, management education for working executives has been essentially located at business school premises in India.

With the proliferation of two way Video Conferencing (VC) facilities across the country, as well as Internet technology, the above-mentioned limitations for students as well as management educators could be effectively overcome. The focus of the $\mathrm{VC}$ technological platform is a powerful user interface that enables a large number of students spatially scattered to have a highly interactive 'one to one' as well as 'one to many' exchange with a centrally located faculty. The system incorporates live broadcast

Copyright (C) 2007 Victoria University. This document has been published as part of the Journal of Business Systems, Governance and Ethics in both online and print formats. Educational and non-profit institutions are granted a nonexclusive licence to utilise this document in whole or in part for personal or classroom use without fee, provided that correct attribution and citation are made and this copyright statement is reproduced. Any other usage is prohibited without the express permission of the in two-way audio and video, it also provides real-time data interactivity to enable the students to watch and interact with the central faculty as well students from other centres, live, on VC facilities. VC technology seems to have potential to play an important role in the proliferation of management education. It is effective in bringing in the teaching competence 
available elsewhere in the world right in the classroom as well as aggregate students from large number of geographical locations to a few distributed web centres or virtual classrooms.

Technology-enabled distance management education has the potential to address the needs of the countries which require skilled managerial manpower in large numbers, and where existing educational infrastructure and resources are not available. Also, distance education has become an important strategic issue for business schools in India as well as worldwide, as it overcomes the restrictions of same-time or same-place learning (Dellana, Collins and West 2000). However, it also provides new challenges to understand and then manage the effectiveness of the programs offered through the emerging technology enabled medium.

To effectively harness the emerging technology, some pedagogical adaptations are required for the educators. These include: course delivery, course materials selection and mechanisms to engage students who are interacting in virtual classrooms. The volume of student to professor interaction may become much higher than the traditional class, and may be difficult to handle, restricting class size (Hirschheim 2005). Similarly, certain adjustments in the students learning models are also required. Like any new technology a process of diffusion is expected. A learning curve effect is expected to help (over time) in fully harnessing the benefits of imparting effective management education on the VC platform. The ground rules for effective teaching through this medium would evolve over time, with the experience of the educators, students and evolution of technology etc.

The debate about the effectiveness of the distance learning method of delivering business courses continues, the results of student satisfaction has been mixed (Campbell and Swift 2006). However, for quick proliferation of the technology enabled distance education in management, understanding the challenges faced by the students as well as faculty is a significant first step. The programs, irrespective of the technology platform used, need to deliver value to the student participants so that the subsequent programs succeed. Thus it is important to understand how the value creation takes place in each of the technological platforms. This research explores this important issue with respect to the VC based Distance Learning (DL) programs.

\section{Practical Managerial Problems Faced}

Management education is quite an established discipline in India (in existence from 1950's and having more than 1000 AICTE approved institutions as on date); pedagogy is reasonably well developed and has been accepted by the industry in India and abroad. The VC based management education offered in DL mode, is just emerging and is a fast evolving field. It needs to evolve and adapt to the current markets to be able to make an impact which is useful for the industry, academia, students and society.

The fundamental issues which make the VC based executive management educational platform different from the standard classroom format are:

a. There is time constraint for the course as well as the classes, thus the structure of the program has to be rigidly followed even at class to class level (rather than the overall course level). Time once lost can not be made up easily.

b. The students are at a distance from the faculty and are clubbed as a group (VC centre wise), hence difficult to build rapport on individual basis, both at the faculty-student and studentstudent level of interaction.

c. The student to student interactions within the centre is uninhibited but across centres is limited at best. Students can not necessarily see all other participants at a time, so within student interaction as well as student-faculty interaction need a protocol for smooth operation.

d. The entire set of student query is unlikely to be addressed within the scheduled class time (due to large class size). Never the less they need to be addressed, and hence the VC mode has to be supplemented in a different (typically) virtual forum. This forum should be comparatively time independent and location neutral in nature, like web based forums, internet, e-mails etc. 
e. The students come from diverse educational as well as professional background and hence there is very large within class discrepancy (in VC mode it tend to persist longer than normal classroom) in the appreciation of the various courses offered in the curriculum. This poses the challenge to the faculty about appropriately pitching the classroom interaction, as well as to manage the outliers subsequently.

f. Regular assignments and evaluation are associated with logistic complexities.

g. To ensure that the service level offered by the technology is acceptable for the educational requirements; is an operational challenge.

h. The students normally do not get to see all the teaching aids together, for example, if the faculty is in the screen, then the board as well as the presentation screen is either out of focus or placed in a smaller window which may not be easy to follow.

Though, the basic aim of education; like meeting the learning objectives of the students, remain unchanged irrespective of the medium and are clear intuitively, but they may require different delivery mechanisms in the VC based DL mode. The delivery effectiveness become difficult to measure objectively as there are some interplay of faculty, course and the technology which necessarily happens in a technology enabled distance education mode. So, it is possible that a particular course is very well designed for the conventional classroom and delivered well by the faculty, would be differently evaluated by the students who have varying of DL.

Formal evaluation of teaching performance by students is now a factor in promotion, tenure, and salary adjustment decision of the faculty (Hooper and Page 86). Also, the effectiveness of the program has significant commercial implications for the institutions offering the course. Thus from the point of view of developing and delivering effective management education through the VC platform, it is important to understand precisely how the learning value is derived by the students. Developing a method to evaluate the effectiveness of distance learning program and faculty effectiveness through the VC mode is the first step.

\section{Literature Review}

The fundamental difference of technology enabled distance education from traditional classroom mode is the physical absence of the instructor, but research findings suggests that it is not an issue for the students as it is considered a constraint and students adjust to it as given. Also, student satisfaction from the courses are also comparable to normal classroom courses (Campbell and Swift 2006).

The key challenges faced in the online distance education has been classified as a set of interdependent issues like content related, delivery related and learning related (Rungtusanatham, Ellram and Siferd 2004). Unique competence is required in the area of course planning, delivery and managing the distributed classroom interaction, and use of appropriate mechanisms of student learning (Davis and Roblyer 2005). These issues give a clue to the basic parameters which could be used to evaluate program effectiveness.

Student evaluation of faculty members should not be compared across disciplines and levels of courses (Whitworth, Price and Randall 2002); however, the students evaluation of the teachers performance are very stable and consistent over time (Tang 1997). However research also indicates that in many cases students evaluation can be statistically reliable and valid (Whitworth et al. 2002). Since a management program is a heterogeneous mix of different disciplines, even though it may not be possible to evaluate the faculty, the program level effectiveness could be measured and evaluation of effectiveness could be possible.

The student performance in the on-line and traditional classroom courses were also found to be same (Dellana et al. 2000), thus the metrics for the program effectiveness, which is measured on commonly used parameters like student learning, the design of the courses, the delivery of the course, academic administration, engaging the students beyond the classroom; could be used. However, online instructors 
role requires a paradigm shift in perceptions of instructional time and space, virtual management techniques and engaging students through virtual communication (Davis and Roblyer 2005). It is expected that the measurement of teaching (and for that matter program) effectiveness will be changed dramatically in future (Tang 1997). Thus new measurement techniques may be useful and required.

There are quite a few studies available in the domain of web based distance education as well as on line education. Similarly there is considerable research data available about measurement of the teaching effectiveness, student learning etc. however, there is no specific literature in the area of predominant use of $\mathrm{VC}$ medium to deliver a long duration management education. Since online learning is getting integrated into many traditional courses, it is important to move beyond making comparison to face to face classes and move towards understanding the specific nuances of the online class as its own unique environment (Conaway et al. 2005). Since the existing literature is not dealing with the specific distance learning programs on $\mathrm{VC}$, the literature survey is only expected to provide the guiding principles. It would also require significant and specific research work to gather insight as well as theory development for newly emerging and fast evolving education through the VC medium.

\section{Methodology Adopted}

VC-based technology is just emerging in India. Reliance Infocomm Limited is providing the VC technology platform across 120 cities in India (and expanding). Though the technology was primarily designed for corporate need to have multi location - multi party conferencing, it was appropriate for the application in DL also. So far, the platform has been used by only one institute, Xavier Institute of Management, Bhubaneswar, India (XIMB); in providing a long duration (300 hours) management program in India as "Post Graduate Certificate in Business Management" (PGCBM). Some other institutes have also offered a few management development programs through this medium, but none in a large scale as XIMB. The "PGCBM" program of XIMB commenced in October 2005. It had 120 participants from 23 centres across 16 cities in India. Since the student base is all India and XIMB is a reasonably well known management institute, the student base would reflect the overall population. The program has been running successfully and regularly till date. Thus it qualified as a good site to study. Annexure 1 gives a detail of the PGCBM program of XIMB.

Significant insights could be generated by studying this site (Yin 1984), seemed to be the most appropriate for the research as:

a. It was a unique case as the Indian executive's who opt for management education are typically looking not only the value addition provided by the program, but also brand image and quick payoff's in the job market.

b. Prior understanding is not available and part of the research is exploratory in nature.

c. Rich context dependent understanding would help in improving the understanding the issues associated in delivering effective executive management education by harnessing the $\mathrm{VC}$ technology.

\section{Stages of the study}

The case study was expected to have two parts. First stage was the exploratory study, called the Exploratory Study, where the objective of the researcher was to understand the different criteria on which the students measured the program effectiveness. Once the first stage was over, in the second stage; a scale was developed to measure how the students processed the different criteria in forming their opinion about the $\mathrm{VC}$ based management program effectiveness.

\section{Details of the study}

a. Choice of techniques: The topic of research was essentially exploratory in nature; the search for appropriate parameters (to evaluate the program effectiveness) required developing a 
common understanding of the student's evaluation criteria. It required deep insights on the learning process of the students, and an initial qualitative research seemed more appropriate to narrow down the criteria on which the program, the courses, and the faculty effectiveness could be subsequently measured quantitatively. Face to face contact with the PGCBM students was expected to facilitate the process.

b. The students of PGCBM program of XIMB were to attend a mandatory 60 hour, spread over one week of On Campus Stay (OCS) as an integral component of the program (refer Annexure 1). Thus the physical presence of the student in the OCS presented the researcher with the opportunity to interact with the students on a face to face basis and conduct the case study research effectively.

Since any course means different things to different participants, there was a very high probability of existence of multiple perspectives about the topic of program evaluation among the students. Gaining information about the shared understanding based on interaction among the participants was critical to the research. Thus, Focus Group Discussion (FGD) was chosen as the primary methodology in developing the evaluation parameters (Malhotra 2004). A small variation to the methodology was attempted by asking the respondent to fill up a their own set of evaluation parameters in an open ended questionnaire, making the finding more amenable to content analysis as well as quantitative analysis, thereby offering a slightly more objectivity than a standard FGD could offer. All the FGD's were video recorded as well as notes were taken by the researcher. Also the study was done in phased manner, with each stage building on the work accomplished in the previous stage.

\section{Operational details}

The total PGCBM batch size was 120, and most of them were expected to be able to attend the OCS in either of the two batches (with a gap of three days in between), henceforth referred to as OCS1 and OCS2 respectively. The batches were formed randomly and thus expected to be equivalent in nature. The batches were also not likely to interact about their experience with each other in detail, thus they could be treated as equivalent for the research purposes.

For making the FGD groups, the students appearing for the OCS1 were selected at random and split into equivalent groups of 10 members each. Each of the groups reflected the heterogeneity which the entire class contained in terms of the student profile (location, educational background, job profile, work experience etc.). Two such groups were used in each stage of the research where focus group discussions were required.

Stage1. Development of the initial dimensions on which the VC based course needed to be measured was developed theoretically as well as using the experience of the researcher and the faculty who had the experience of teaching in the VC platform. The FGD protocol is attached in Annexure 2. FGD of students (2 FGD having 10 participants each) were conducted to develop a master set of criteria which were considered relevant by them for evaluating the VC based courses.

Stage2. The FGD's in Stage 1 were analyzed, collated and a master list of criteria for evaluation of courses offered in VC mode was developed. A second phase of FGD's of students (2 FGDs of 8 participants each) was conducted to develop the relevant mapping of the criteria to the different developed dimensions. Thus the first level of evaluation criteria for the overall program and the sub criteria was developed. Based on the analysis of the FDG's in Stage1 and Stage 2, twenty-five (25) different criteria were found relevant and are given in Annexure 3. The criteria were analyzed by researchers and classified under the following heads: Learning Value, Course Design, Course Delivery, Course Administration and Interest Generation. The tabulation details are given in Annexure 4, and the final parameters decided, in Annexure 5.

The faculty members with teaching experience of at least 3 number 3 credit courses and had not taught in the VC mode (though aware of the medium and its challenges) were asked to validate the result of the step 3. Their suggestions were incorporated. The items of the scale so far developed were then suitably adjusted to convert them into statements as required by Likert scale. Thus the initial completed scale 
was developed, given in Annexure 6. This was administered to the students attending OCS1. The reliability of the measures was not up to acceptable mark and hence was further modified using the existing literature (Stapleton and Murkison 2001; Rungtusanatham et al. 2004; Davis and Roblyer 2005). Thus the validity was incorporated in the scale by the help of existing literature on validated scales as well as expert opinion of faculty. Constructs were redefined as: Course Effectiveness, Teaching Effectiveness, Evaluation Effectiveness, Technology Effectiveness, Student Learning, Course Feedback and Program Feedback. The details are given in Annexure 6. The scale was formatted to a questionnaire form (Annexure 7) and administered to the students of OCS2. The questionnaire was filled up by 54 participating students for six different faculty members who had conducted at least 8 hours of classes in the VC for them (and not had any normal classroom interaction). In all 42 (sets of 6) completed responses were collected. The Cronbach's alpha reliability figures were satisfactory and complete information is given in Annexure 8.

\section{Development of Theoretical Constructs for Student Evaluation of a VC-Based management Program Based on the Exploratory Study}

The seven different parameters were the ones clearly identified as the basic parameters which were used by the students to evaluate the usefulness of the course. The researcher hypothesized that out of these, four parameters; Course Effectiveness (CE), Teaching Effectiveness (TE), Evaluation Effectiveness (EE) and Technology Effectiveness (TECE) lead to Student Learning (SL) from the course. The assumption being, the objective of attending the program for the student was to enhance their learning. The student learning was thus expected to impact their assessment of the individual course or the Course Feedback (CF). Since, the entire program was essentially aggregation of many courses, the student's evaluation of the program, or the Program Feedback (PF) would depend on the course feedbacks. The following was the schematic representation of the construct (Fig 1):

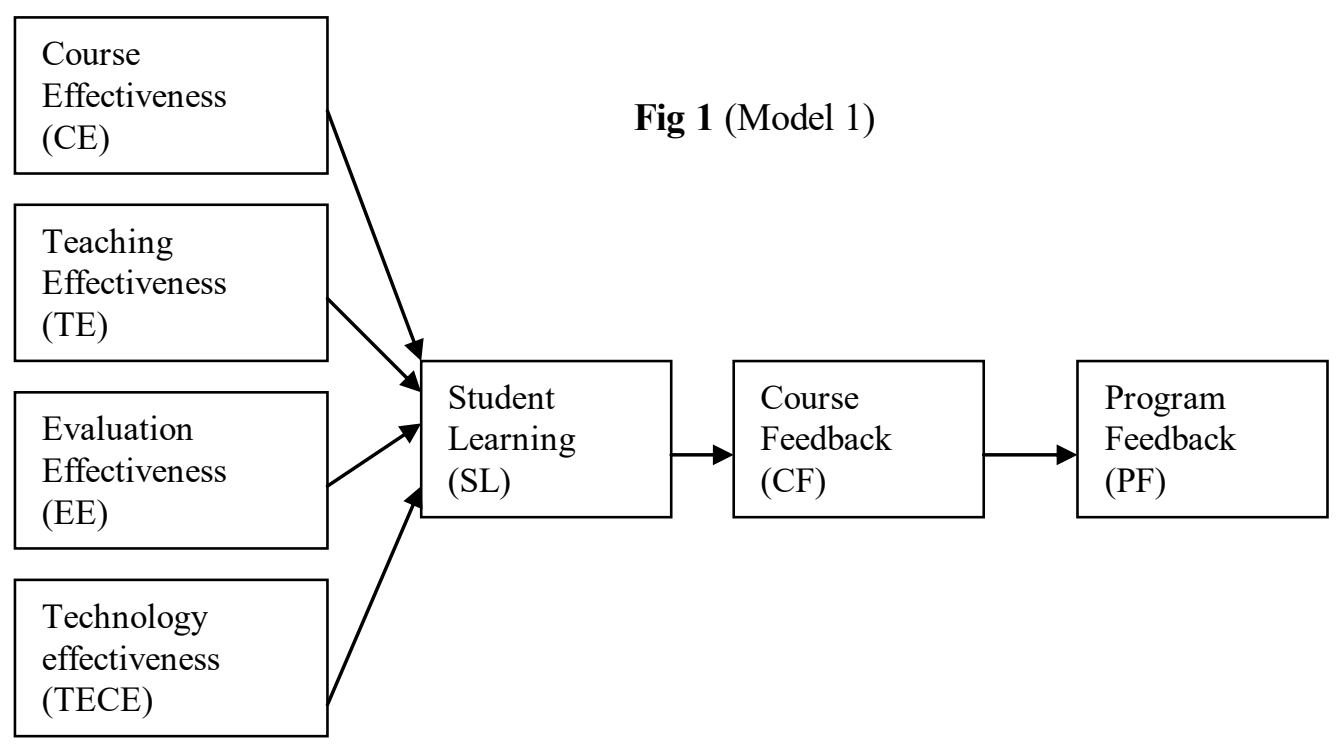

\section{Testing the Theoretically Developed Framework of Student Evaluation of VC-Based Management Education}

The variables in the construct were measured by taking the average of at least four separate questions (as per the scale developed, and given in annexure7). It was appropriate to employ the model fitting technique to understand the student's evaluation process and underlying evaluation construct. AMOS software to analyse using structural equation modelling was chosen (Malhotra 2004) as: (i) Variables were interdependent in nature (ii) More than one variable could determine another variables (iii) 
Technique calculated all the figures simultaneously (iv) Built in tolerance for errors in measurement of the variables.

Step1: The theoretically developed model (Model 1) was tested for fit with the data. The Discrepancy figures per degree of freedom, The Adjusted Goodness of Fit Index (AGFI), Tucker Lewis Index (TLI) and the RMSEA were the measures used to evaluate the model fit. The fit measures were not reflecting a good fit of the Model 1, to the data collected (Annexure 9). The effect of TECE and TE on SL, were found to be insignificant. Thus it was concluded that the theoretically developed model did not fit the data well, and required to be modified.

Step2: Based on the results, Model 1 was modified. Since in Model1, TECE and TE did not make significant impact on the SL, they were dropped in the revised model. The revised model was named "Model 2" (which was essentially Modell sans the TE and TECE). There was a considerable improvement in the fitness measures, yet they were not up to the acceptable level.

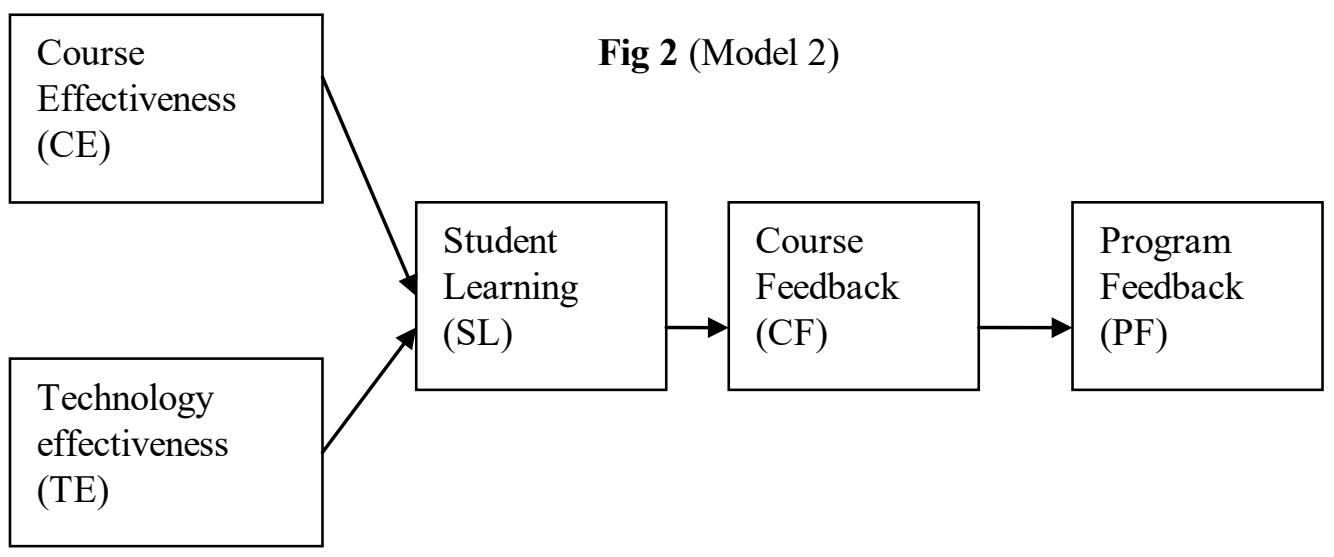

Step3: Since each of the variables in Model 2 was significant, there was no possibility of dropping any of the variables. There was a need to re-conceptualize the framework. Literature (Karstebsson and Vedder 1974), and discussion with experienced faculty suggested that, the student learning may be based on their own interest in the subject, self motivation, relevance to their own work etc. Thus student learning could be an independent variable in the framework and not dependent on any other variable(s). Thus the Model 2 was modified significantly to convert student learning as an independent variable, keeping the rest same. Fit measures were calculated for Model 3. The fit measures are given in the Annexure 9. The fit measures were found to meet the acceptance criteria put for the all the measures, and thus the model was accepted, which is given in Figure3.

Figure 3 (Model 3)

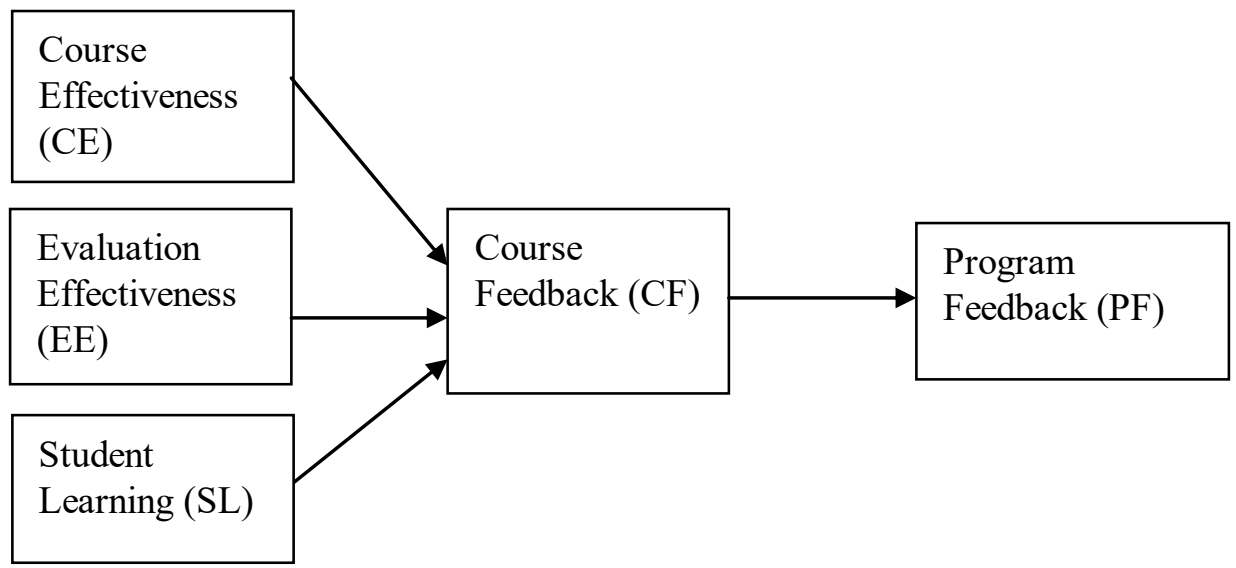

Step 4: Alternate frameworks to improve the fit were tried out but they were not found to improve upon the results derived from the Model 3. Thus they are not reported. 


\section{Implications of the Study}

a. The scale to measure the program effectiveness of the VC based DL programs could be used as a reliable tool for future use.

b. The teaching effectiveness did not emerge as important criteria for the student's evaluation of the program effectiveness, while course effectiveness and evaluation effectiveness did. It is possible that a very well designed course and evaluation system may be offered by different faculty members quite effectively without significantly altering the student satisfaction. Thus, teaching in this medium could be developed more in a process based manner rather than faculty skills. More structured delivery with average faculty skills may be adequate. Thus the finding supports the "design-team driven model" approach to course content design and program design in the medium (Rungtusanatham et al. 2004).

c. It is possible to scale up the program quite conveniently. For the success of the program, the critical aspects are the program design, evaluation process and student motivation to learn as compared to teaching effectiveness and technology. Thus a well developed course by an expert(s) with very clear evaluation parameters may be quickly disseminated to a large number of faculty (through a train the trainer program) to conduct the classes effectively. So the faculty constraints could be effectively overcome and the program could be expanded.

d. Technology Effectiveness did not come across as important parameter to students, possibly the technology was new, and the student expectation were not much out of the same. The limitations of the technology were possibly well understood and internalized by the students or novelty of the new technology also could possibly have suppressed its differentiating impact on the program. It could be like a hygiene factor, it is not a motivator. However, if it is not of acceptable standard then it could possibly act as an irritant. Overall, it is possible that the medium makes the technology such a given parameter that it doesn't remain a differentiator. The implication is that, focusing on the course design, evaluation process and admission criteria for students are equally important (if not more) as constant endeavor to improve technologically in the medium and offer superior interaction.

e. The student learning did not come as a dependent variable, instead as an independent variable. The implication is that student learning may depend on factors which are beyond the factors studied in the research, for example, it could be the individual student's interest in the subject, ability to grasp concepts, readiness to do self learning etc. Thus the feedback of the program may depend largely on the student's interest in learning rather than the program per se. Thus the student's motivation to join and learn from the program was of vital importance. As a corollary, the screening of the students in the admission process would assume critical importance.

\section{Limitations of the Study and Scope for Further Research}

a. The study was conducted only on one program (as there was no other site at the time of the research) further studies are required to confirm the findings.

b. The students were the early adopters of this mode of learning, as they were the first group of students who adopted the technology. Thus the students group studied might not reflect the entire population and more significantly the future student population.

c. The program studied in this research, itself is in the development stage and hence is undergoing a lot of pedagogical experimentation, which might have biased the responses and thereby the conclusions. Hence the study conducted with the students of the subsequent batches might be useful and more dependable.

d. The framework of student evaluation of management program, developed by this research could also be tested with student undergoing the classroom programs and their criteria for program effectiveness could also be compared. 


\section{References}

Campbell, C. R. and Swift, C. O. (2006). "Perceptions of Compressed Video Distance Learning (DL) Across Location and Levels of Instruction in Business Courses." Journal of Education for Business(January/February).

Conaway, R. N., Easton, S. S. and Schimdt, W. V. (2005). "Strategies for enhancing student interaction and immediacy in online courses." Business Communication Quarterly 68(1): 23-35.

Davis, N. E. and Roblyer, M. D. (2005). "Preparing teachers for the "Schools That Technology Built": Evaluation of Program to Train Teachers for Virtual Schooling." Journal of Research on Technology in Education 37(4): 399-409.

Dellana, A. S., Collins, H. W. and West, D. (2000). "On-Line Education in a Management Science Course - Effectiveness and Performance Factors." Journal of Education for Business September/October: 43-47.

Hirschheim, R. (2005). "The Internet-Based Education Bandwagon: Look Before You Leap.” Communications of the ACM 48(7): 97-101.

Hooper, P. and Page, J. (86). "Measuring Teaching Effectiveness by Student Evaluation." Issues in Accounting Education 1(1): 56-64.

Karstebsson, L. and Vedder, R. K. (1974). "A note on attitude as a factor in learning economics." Journal of Economic Education 5(2): 109-111.

Malhotra, N. K. (2004). Marketing Research. New Jersey, Prentice-Hall.

Rungtusanatham, M., Ellram, L. M. and Siferd, S. P. (2004). "Towards a Typology of Business Education in The Internet Age." Decision Sciences Journal of Innovative Education 2(2): 101-120.

Stapleton, J. R. and Murkison, G. (2001). "Optimizing the fairness of student evaluations: A study of correlation between instructor excellence, study production, learning production, and expected grades." Journal of Management Education 25(3): 269-291.

Tang, T. L. P. (1997). "Teaching Evaluation at a Public Institution of Higher Education: Factors Related to the Overall Teaching Effectiveness." Public Personnel Management 26(3): 379-389.

Whitworth, E. J., Price, A. B. and Randall, H. C. (2002). "Factors That Affect College of Business Student Opinion of Teaching and Learning." Journal of Education for Business 77(5): 282-289.

Yin, R. K. (1984). Case study research - Design and Methods. Beverly Hills, Sage Publication. 
Annexure 1 (Details about the PGCBM program of XIMB)

XAVIER INSTITUTE OF MANAGEMENT, BHUBANESWAR

POST GRADUATE CERTIFICATE PROGRAM IN BUSINESS MANAGEMENT (PGCBM)

\section{ADMISSION PROCEDURE}

Eligibility: The minimum requirement for admission to the Program is A three-year Bachelor's degree (or equivalent) in any discipline recognized by the Association of ndian Universities as eligible for Post-Graduate studies in Management and with at least two years work experience

XIMB PGCBM Prospectus \& Application: The cost of the PGCBM Prospectus is Rs 800 The applicants can obtain the PGCBM Prospectus from the nearest Reliance Webworld in person or from the XMB office counter in person by cash payment Each PGCBM prospectus carries a unique User D and Password for each student which would be used to access the XMB PGCBM website for online student registration The student would use the User $D$ and Password to fill up the online application form at the XMB Website (www ximb ac in) Once registered the student would have access to the X MB web where relevant information regarding admissions would be posted from time to time

Selection Process: After review of the candidate profiles XMB would intimate the short-listed candidates regarding the venue and time for their interview The interviews would be held through Video Conferencing from certain identified Reliance Webworlds The final selection will be based on the candidate's performance in the Personal nterview (which factors in the past academic record and relevant work experience) The selected candidates will be informed by mail by September 202005

Admission: Candidates who are selected for admission to the Post-Graduate Program must indicate their acceptance of the admission offer and all related conditions by paying the first instalment of fees as detailed in the letter of admission before the date stipulated therein The classes would begin by the end of October 2005 At this time the students will be given a Manual of Policies and Regulations which will be binding on them

\section{ACADEMIC SYSTEM - PGCBM}

Program Design: The Program consists of 12 courses namely

1 Cost \& Management Accounting

3 Organizational Behaviour

5 Financial Management

7 Production \& Operations Management

9 nformation Technology for Managers

11 Strategic ssues in Management
2 Basic Economics for Managers

4 Quantitative methods for Business Decisions

6 Human Resource Management

8 Marketing Management

10 Ethical \& Legal Environment of Business

12 Emerging Business Paradigms

Academic Calendar: The entire program consists one year duration having 240 hours of live video conferencing and 60 hours of rigorous oncampus classes at X MB spread over one week duration

Certification: The nstitute awards the Post Graduate Certificate Program in Business Management to students who have successfully completed the entire course work and have successfully completed all academic requirements as mentioned in the Manual of Policies The Manual of Policies would be provided to those students who are admitted to the program

\section{ON CAMPUS STAY at XIMB}

The PGCBM program includes a seven-day on-campus stay at XMB During this one-week the students would be exposed to 60 hours of rigorous real-time classroom interaction by the renowned X MB faculty A number of skill development programs which require intense group activities The students would have access to world-class facilities of XMB

\section{Annexure 2 (PGCBM Focus group discussion brief - FGD protocol)}

PGCBM program offered by XIMB is the first ever video conferencing based course to be offered in the country Catering to a diverse mix of time starved and location bound students; the program seems to have started off well and has a bright future Powered by the state of the art technology, the program is demanding for both faculty and student, in terms of acquaintance with the system itself

Given our experience in the past couple of months, certain issues have emerged which need to be addressed in a common platform:

1 The students of this program consist of a heterogeneous mixture coming from different locations and various backgrounds This has made program design and delivery a difficult task

2 Time and distance being the binding constraints, have added to the complexity of the programs in terms of administration and evaluation

3 The application of videoconferencing technology to the education industry is new This calls for an adaptation in the teaching methodology or development of a new methodology altogether

4 In order to optimise the take away for both student and faculty, the technology needs to be harnessed fully At the same time, caution needs to be exercised towards the inherent biases that the technology brings in

Improvement is a continuous process driven by awareness of environment Given the vivid experience that each one of us has had till now, it is essential for us to sit back and take note of what has transpired This focus group discussion is an attempt to get an insight to the subtler issues involved in the PGCBM program

Participants are encouraged to feel free in expressing their views The output of this discussion shall be used purely for research purpose and the development of the PGCBM program Constructive feedback and critical reasoning shall be appreciated We shall try to keep our discussion focused on to the following points:

The expectations of the students from: Course, Faculty, Technology

What are the key ingredients of the program package that can not be compromised with?

What are the features that add value to such a program?

Any new features that you would like to have in the program?

What are the basic skills that students of such a program look for in a faculty?

What are the features that need to be incorporated to

a Keep the students engaged in the class?

b Keep the students engaged outside the class?

7 Any drawbacks of the technology that has been noticed? What could be the possible changes required in the technology front to suit to the needs of the student?

$8 \quad$ Any other difficulty faced during the program?

(Participants are supposed to list down the criteria on which a PGCBM faculty should be evaluated A minimum of 10 criteria are required They need to be in order of importance The most important one has to be written first Rough work will be allowed) 
Annexure 3 ( The list of the 25 parameters which were found relevant in FGD 1 \& 2)

\begin{tabular}{|r|l|}
\hline \multicolumn{1}{|c|}{ Serial No } & \multicolumn{1}{|c|}{ tem } \\
\hline 1 & Ability of the faculty to clear the fundamentals of the subject \\
\hline 2 & Clarity of concepts explained in the course \\
\hline 3 & Ability of the faculty to complete the planned session in time \\
\hline 4 & The relevance of the course in your work life \\
\hline 5 & Ability of the faculty to motivate the students to participate in the A S discussion forum \\
\hline 6 & Ability of the faculty in making the course relevant to the students \\
\hline 7 & Ability of the faculty to motivate the students to engage in self learning \\
\hline 8 & Ability of the technology to enable the students to engage in self learning \\
\hline 9 & The adequateness of the course materials distributed by the faculty \\
\hline 10 & Practical orientation of the course \\
\hline 11 & The appropriateness of VC technology in delivering the particular course \\
\hline 12 & Regularity of evaluation \\
\hline 13 & Transparency of evaluation \\
\hline 14 & Value addition achieved by the students attending the course \\
\hline 15 & Adhering to predetermined structure of the program \\
\hline 16 & Pre class preparation of faculty \\
\hline 17 & Faculty responsiveness in the A S \\
\hline 18 & Use of different evaluation parameters for testing the learning of the students \\
\hline 19 & Examination which evaluates the application of concepts by the students \\
\hline 20 & Ability of the faculty in making the classes interesting to students \\
\hline 21 & Ability of the faculty to utilize the technology effectively \\
\hline 22 & Course administration by faculty \\
\hline 23 & Ability of the faculty to make the class interactive \\
\hline 24 & Ability of the faculty in engaging students in the class \\
\hline 25 & Ability of the faculty in developing appropriate assignments \\
\hline
\end{tabular}

Annexure 4 (Tabulation of the clubbing of criteria by participants of FGD3 \& 4)

\begin{tabular}{|c|c|c|c|c|c|c|}
\hline S.No & Item & $\begin{array}{l}\text { Learning } \\
\text { Value }\end{array}$ & $\begin{array}{l}\text { Course } \\
\text { Design }\end{array}$ & $\begin{array}{l}\text { Course } \\
\text { Delivery }\end{array}$ & $\begin{array}{l}\text { Course } \\
\text { Admin. }\end{array}$ & $\begin{array}{l}\text { Interest } \\
\text { Generation }\end{array}$ \\
\hline 1 & $\begin{array}{l}\text { Ability of the faculty to clear the fundamentals of the } \\
\text { subject }\end{array}$ & 8 & 0 & 3 & 0 & 3 \\
\hline 2 & Clarity of concepts explained in the course & 5 & 5 & 0 & 0 & 3 \\
\hline 3 & $\begin{array}{l}\text { Ability of the faculty to complete the planned session in } \\
\text { time }\end{array}$ & 0 & 5 & 5 & 2 & 3 \\
\hline 4 & The relevance of the course in your work life & 6 & 2 & 0 & 0 & 6 \\
\hline 5 & $\begin{array}{l}\text { Ability of the faculty to motivate the students to } \\
\text { participate in the AS discussion forum }\end{array}$ & 4 & 4 & 3 & 0 & 2 \\
\hline 6 & $\begin{array}{l}\text { Ability of the faculty in making the course relevant to the } \\
\text { students }\end{array}$ & 2 & 6 & 3 & 0 & 3 \\
\hline 7 & $\begin{array}{l}\text { Ability of the faculty to motivate the students to engage } \\
\text { in self learning }\end{array}$ & 1 & 4 & 5 & 2 & 3 \\
\hline 8 & $\begin{array}{l}\text { Ability of the technology to enable the students to } \\
\text { engage in self learning }\end{array}$ & 1 & 6 & 3 & 2 & 2 \\
\hline 9 & $\begin{array}{l}\text { The adequateness of the course materials distributed } \\
\text { by the faculty }\end{array}$ & 0 & 9 & 4 & 1 & 1 \\
\hline 10 & Practical orientation of the course & 3 & 5 & 2 & 1 & 1 \\
\hline 11 & $\begin{array}{l}\text { The appropriateness of VC technology in delivering the } \\
\text { particular course }\end{array}$ & 0 & 1 & 6 & 4 & 2 \\
\hline 12 & Regularity of evaluation & 2 & 1 & 2 & 3 & 1 \\
\hline 13 & Transparency of evaluation & 1 & 3 & 1 & 6 & 1 \\
\hline 14 & $\begin{array}{l}\text { Value addition achieved by the students attending the } \\
\text { course }\end{array}$ & 5 & 0 & 4 & 1 & 2 \\
\hline 15 & Adhering to predetermined structure of program & 0 & 4 & 2 & 6 & 1 \\
\hline 16 & Pre class preparation of faculty & 0 & 0 & 7 & 3 & 2 \\
\hline 17 & Faculty responsiveness in the AS & 0 & 1 & 1 & 2 & 7 \\
\hline 18 & $\begin{array}{l}\text { Use of different evaluation parameters for testing the } \\
\text { learning of the students }\end{array}$ & 2 & 1 & 2 & 8 & 0 \\
\hline 19 & $\begin{array}{l}\text { Examination which evaluates the application of } \\
\text { concepts by the students }\end{array}$ & 5 & 0 & 0 & 7 & 3 \\
\hline 20 & $\begin{array}{l}\text { Ability of the faculty in making the classes interesting to } \\
\text { students }\end{array}$ & 1 & 0 & 1 & 1 & 9 \\
\hline 21 & Ability of the faculty to utilize the technology effectively & 0 & 0 & 4 & 4 & 4 \\
\hline 22 & Course administration by faculty & 1 & 1 & 1 & 6 & 4 \\
\hline 23 & Ability of faculty to make the class interactive & 0 & 1 & 1 & 1 & 10 \\
\hline 24 & Ability of faculty in engaging students in class & 0 & 1 & 1 & 1 & 10 \\
\hline 25 & $\begin{array}{l}\text { Ability of the faculty in developing appropriate } \\
\text { assignments }\end{array}$ & 3 & 1 & 1 & 2 & 8 \\
\hline
\end{tabular}


Annexure 5 (Parameters for evaluation of program as per exploratory study)

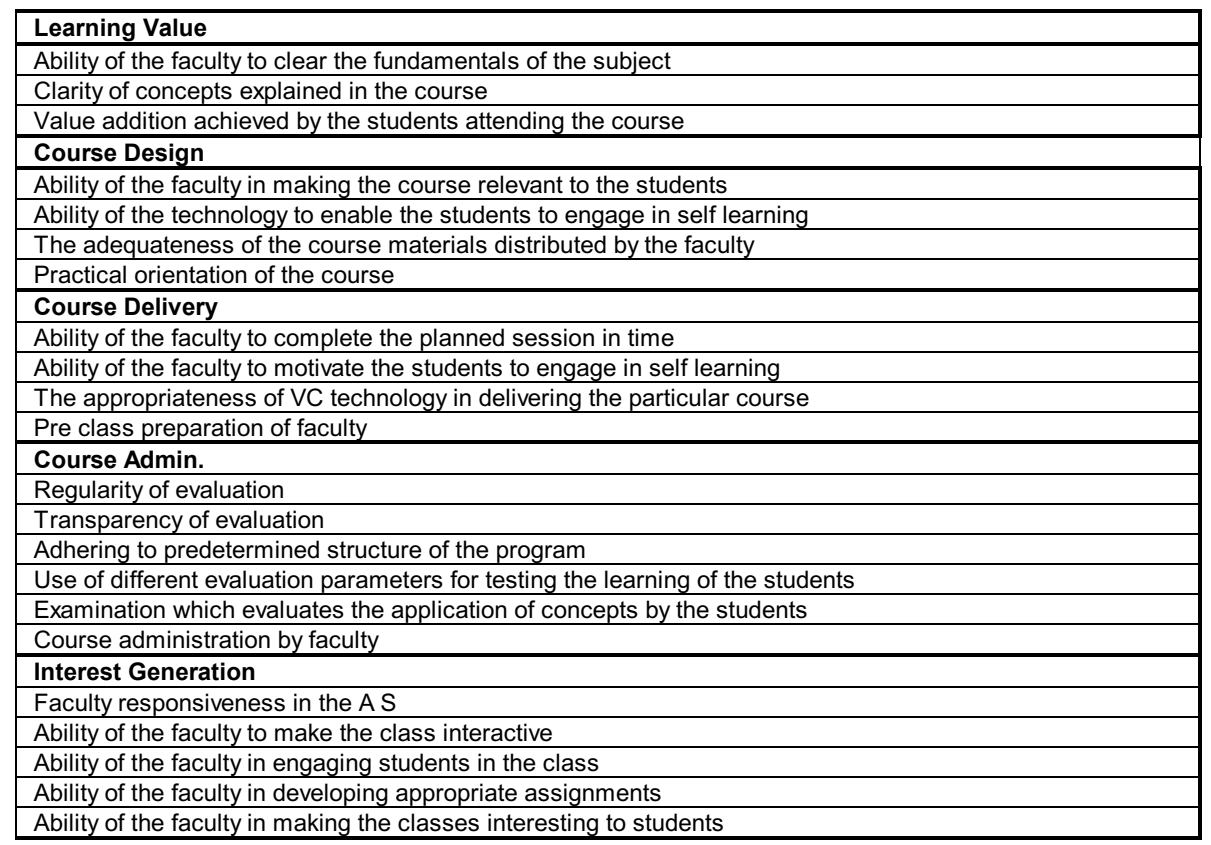

Annexure 6 (Measurement scale Used for the research)

\begin{tabular}{|c|c|}
\hline S. No & Course effectiveness \\
\hline 1 & The subject matter was relevant \& useful \\
\hline 2 & The course was interesting and stimulating \\
\hline 3 & The course was intellectually challenging \\
\hline \multirow[t]{2}{*}{4} & The workload was consistent with the value of the course \\
\hline & Teaching effectiveness \\
\hline 5 & The instructor was able to present the concepts clearly \\
\hline 6 & The instructor could answer the student queries satisfactorily \\
\hline 7 & The instructor had healthy respect for students \\
\hline 8 & The instructor was prepared for the classes \\
\hline \multirow[t]{2}{*}{9} & Overall the instructor was one of the best have ever had \\
\hline & Evaluation effectiveness \\
\hline 10 & The exams were fair \\
\hline 11 & The projects and assignment were beneficial \\
\hline 12 & The quizzes and exams were able to check the understanding of the students \\
\hline 13 & The quizzes conducted were relevant \\
\hline \multirow[t]{2}{*}{14} & The evaluation was consistent and fair \\
\hline & Technology effectiveness \\
\hline 15 & The technology was creatively used in the course \\
\hline 16 & The A S was effectively used during the course to help in learning \\
\hline 17 & The technology helped enhance the overall learning experience \\
\hline 18 & The content presentation in VC platform was satisfactory \\
\hline \multirow[t]{2}{*}{19} & The course web in A S was well organized \\
\hline & Student learning from course \\
\hline 20 & was able to derive value from the course \\
\hline 21 & New ideas and applications were learnt \\
\hline 22 & am enthused to learn more about the subject \\
\hline \multirow[t]{2}{*}{23} & The coverage of the course was adequate given the time constraint \\
\hline & Course feedback \\
\hline 24 & Overall the course was useful \\
\hline 25 & would recommend the course to others \\
\hline 26 & Compared to other courses this course was one of the best \\
\hline 27 & The course was able to add value to me \\
\hline \multirow[t]{2}{*}{28} & This course is an important component of the overall program \\
\hline & Program feedback \\
\hline 29 & am satisfied with the program \\
\hline 30 & would recommend the program to others \\
\hline 31 & The program as a whole is adding value to me \\
\hline 32 & My objective of joining the program are being met \\
\hline
\end{tabular}


Annexure 7 (Questionnaire Used for the study)

Evaluate the abovementioned course taken by the particular faculty with respect to the following statements in a scale, strongly agree, agree, neither agree or disagree, disagree and strongly disagree.

“Course Feedback for PGCBM” - QMBD (A) By Prof. G.K. NAYAK

\begin{tabular}{|c|c|}
\hline S.no & Statement \\
\hline 1 & Assignments given were relevant to the course \\
\hline 2 & Concepts were clearly explained in the course \\
\hline 3 & Faculty was adequately prepared for the class \\
\hline 4 & The course motivated me to engage in self learning \\
\hline 5 & The course design induced me to participate in the AS discussion forum \\
\hline 6 & Faculty made the classes interactive \\
\hline 7 & The course materials given were adequate \\
\hline 8 & The course adhered to the predetermined structure of the program \\
\hline 9 & The evaluation method adopted was transparent \\
\hline 10 & The course had the desired practical orientation \\
\hline 11 & The planned class coverage were completed in time \\
\hline 12 & Examinations evaluated the application of concepts \\
\hline 13 & Faculty was successful in clearly explaining the fundamentals of the subject \\
\hline 14 & Faculty took care of my individual learning needs \\
\hline 15 & Expected value addition was achieved by me from the course \\
\hline 16 & The delivery style helped in making the course relevant to my work life \\
\hline 17 & The technology was effectively used to help me in self-learning in the subject \\
\hline 18 & Feedback given by the faculty was timely \\
\hline 19 & Faculty responsiveness in the AS was adequate \\
\hline 20 & My learning was regularly evaluated \\
\hline 21 & VC technology is suitable for delivering the course \\
\hline 22 & The classes were interesting to me \\
\hline 23 & The course is useful in my work life \\
\hline 24 & Technology was utilized effectively in the conduct of the course \\
\hline 25 & My learning achieved was tested in various ways during the evaluation \\
\hline
\end{tabular}

Annexure 8 (Reliability test results of the different parameters measured)

\begin{tabular}{|l|c|c|c|}
\hline \multicolumn{1}{|c|}{ Parameter } & No of Cases & No of tem & Alpha Scores \\
\hline Course Effectiveness & 281 & 4 & 08732 \\
\hline Teaching Effectiveness & 282 & 5 & 08933 \\
\hline Evaluation Effectiveness & 261 & 5 & 0907 \\
\hline Technological Effectiveness & 282 & 5 & 08986 \\
\hline Student Learning & 282 & 4 & 08414 \\
\hline Course Feedback & 282 & 5 & 09245 \\
\hline Program Feedback & 282 & 4 & 0872 \\
\hline
\end{tabular}

Annexure 9 (Model Fit Data - Summary)

\begin{tabular}{|l|c|c|c|c|c|c|}
\cline { 2 - 6 } \multicolumn{1}{c|}{} & Discrepancy & $\begin{array}{c}\text { Degrees of } \\
\text { Freedom }\end{array}$ & Discrepancy / d. of f. & Adjusted GFI & TL I & RMSEA \\
\hline Model 1 & 6247 & 9 & 694 & 069 & 086 \\
\hline Model 2 & 3007 & 5 & 601 & 077 & 0291 \\
\hline Model 3 & $\mathbf{4 . 3 9}$ & $\mathbf{3}$ & $\mathbf{1 . 4 6}$ & 0.94 & $\mathbf{0 . 9 9}$ & $\mathbf{0 . 0 6}$ \\
\hline
\end{tabular}


